\title{
Development rate, flower growth and production of Anthurium
}

\author{
D. Klapwijk and H. J. H. van der Spek \\ Glasshouse Crops Research Station, P.O. Box 8, NL 2670 AA Naaldwijk, Nether- \\ lands
}

Received 29 December 1987; accepted 31 March 1988

Key words: Anthurium, leaf plastochron, flower growth, flower production, flower abortion

\begin{abstract}
In a commercial nursery year-round data were collected concerning leaf plastochron, flower growth and bud abortion in Anthurium. Additional data were derived from a great number of growers with respect to year-round production of this crop.

The leaf plastochron duration was found to be fairly constant from March until September with an average of 72 days. Around 10 October the duration was more than doubled. Subsequently it decreased linearly to 72 days again, resulting in a high leaf production around April. Leaf plastochron seems to be related to radiation. Daylength is probably not involved, as leaf emergence continued during winter. In winter, the maximum period between emergence and harvest of flowers was found around 21 December. The minimum growth period was found in June-July.

Flower production fluctuated strongly, with a minimum in March and a maximum in the second half of June. This maximum is related to the high leaf production in February-March. Presumably the minimum production in March is the result of a severe abortion rate of flower buds in December. The year-round average of the abortion rate was approximately $50 \%$, probably being almost $100 \%$ in December.
\end{abstract}

\section{Introduction}

Recently the profitability of the Anthurium culture decreased in the Netherlands, because increase in acreage resulted in lower prices, especially during the production peak in summer. The profitability of the crop can be improved by shifting the production peak from summer to spring and autumn. To investigate whether this shift is possible more insight into the seasonal effects on growth and development is needed. To obtain more information on seasonal behaviour of Anthurium, yearround data were collected concerning leaf plastochron, flower growth, flower bud abortion and commercial production pattern. 


\section{Materials and methods}

Eleven different clones of Anthurium andraeanum (Lind.) were grown from February 1983 to January 1984 under commercial conditions in a standard Venlo greenhouse which was lime-shaded from April till September. These 11 clones are representing the Anthurium clones used in the Netherlands and therefore give a general impression about the characteristics of the material used for commercial production. Water, plant nutrients and temperature were applied according to practical standards. Of every clone, 10 shoots were chosen at random. Plant density was approximately 6 plants per $\mathrm{m}^{2}$.

The use of these 11 clones as replicates of the experiment, was justified by preliminary results which showed a rather equal response of all clones to seasonal changes; on average $33 \%$ of the annually produced number of leaves emerged between October and February, with a variation amongst clones of 30.6-35.2\% (Klapwijk, unpublished data).

The annual cycle (February 1983-January 1984) of the plastochron was determined by recording every new leaf on a particular shoot at about 3-week intervals as soon as it was macroscopically visible. The same was done with flower buds, of which the period between emergence and harvesting was determined. The leaf plastochron is defined as the period between the identical developmental stages of two successive leaves. The stage employed was the visibility of leaf emergence from the leaf sheath.

For the 11 clones used the annual production (number of flowers) of the total population was available over the same period. Additionally a set of year-round production data from 27 commercial nurseries was used.

\section{Results and discussion}

\section{Leaf plastochron}

Fig. 1 shows that the leaf plastochron is fairly constant from the beginning of March until the beginning of October. The average duration is 72 days, which implies approximately 3.5 leaves per shoot. During this period, neither radiation level nor daylength seems to be very important with respect to leaf initiation rate. At the beginning of October the leaf plastochron increased sharply to more than 150 days. Beyond this moment the duration decreased linearly during a 120 -day period (October-February), from 152 till 72 days. During this period of the year, only 1.5 leaves per shoot appeared. The decrease of the leaf plastochron was $152-72=80$ days during a 120-day period, which implies that for every day delay in leaf emergence the plastochron decreased with 0.67 day. There seems to exist a certain threshold in the growing conditions around 10 October, which inhibits the emergence of new leaves, resulting in an abrupt extension of the interval between two successive leaves. However, shoots show differences in individual vigour, as beyond 10 October some shoots produced their next leaf still at the short duration, and others produced their next leaf after a long duration already emerging some weeks before 10 Octo- 


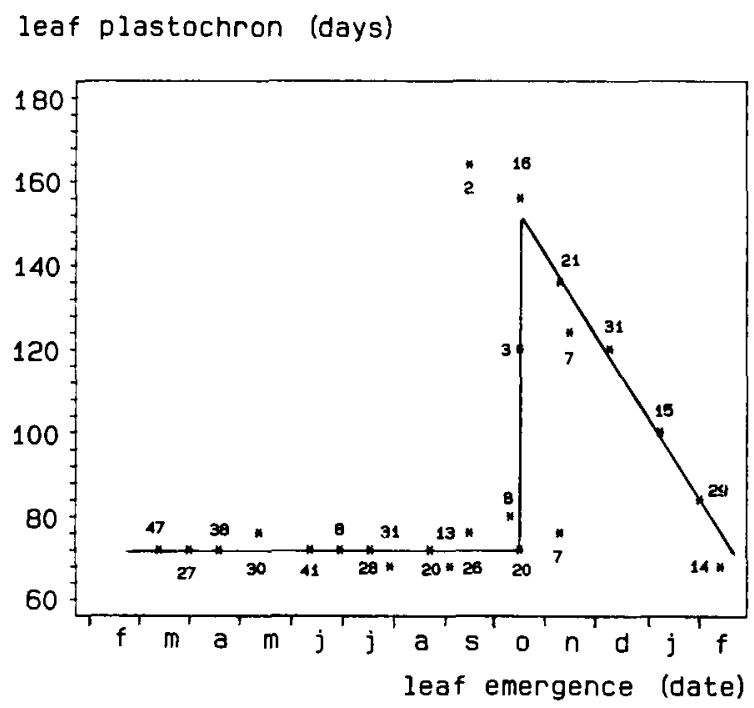

Fig. 1. Leaf plastochron (days) in Anthurium plotted against the date of leaf emergence. The numbers in the curve indicate the number of emerging leaves.

ber (Fig. 1). Daylengths are not the cause of this phenomenon as leaves are emerging at far shorter daylengths in December. At the natural light levels in a glasshouse after approximately 10 October, which implies an outside global radiation lower than $600 \mathrm{~J} \mathrm{~cm}^{-2} \mathrm{day}^{-1}$, a number of meristems seems to stay more or less dormant (for radiation and daylength under Dutch meteorological conditions, see Table 1). There is no current explanation for the appearance of a relatively large number of leaves during the period November-January.

Table 1. Average radiation (1971-1986) and average daylength at the Glasshouse Crops Research Station. Naaldwijk. Netherlands.

\begin{tabular}{lcc}
\hline Month & $\begin{array}{l}\text { Radiation } \\
\left(\mathrm{J} \mathrm{cm}^{-2} \mathrm{~d}^{-1}\right)\end{array}$ & $\begin{array}{l}\text { Daylength } \\
(\mathrm{h})\end{array}$ \\
January & 7236 & 8.1 \\
February & 13760 & 10.0 \\
March & 25988 & 11.9 \\
April & 41293 & 13.9 \\
May & 54670 & 15.9 \\
June & 58678 & 16.9 \\
July & 56439 & 16.2 \\
August & 48004 & 14.1 \\
September & 31377 & 12.1 \\
October & 18801 & 10.3 \\
November & 8575 & 8.8 \\
December & 5608 & 7.9 \\
\hline
\end{tabular}


The decreasing duration may be the result of increasing solar energy in spring. As growers are lime-shading their glasshouses during summer, it seems to be worthwhile to remove the shading material as soon as possible. Another suggestion is to investigate whether artificial light may be of use to stimulate leaf emergence, as in the axil of each leaf a flower bud is initiated (Voigt Christensen, 1971). Between mid-October and mid-February the duration decreased linearly with 20 days for every month leaf emergence is delayed. This implies that all leaves emerging during this period are followed by the consecutive leaves between mid-March (mid-October +150 days) and the end of May (mid-February +100 days). This is demonstrated by the large number of emerging leaves $(47+27+38+30=142)$ during March-May (Fig. 1), which is $30 \%$ of the year-round leaf production. Assuming that leaf and flower initiation are interdependent, this high leaf production should be followed at any time by a flower production peak.

\section{Flower growth}

In Fig. 2 the period between flower bud emergence and harvest is plotted against the date in the middle of this growing period (mid-date, Klapwijk, 1979). The minimum growing period was not very precisely correlated with 21 June. This may be partially explained by the irregular shading which is applied by the growers during the summer. During winter the maximum duration was found around 21 December. By this increasing growth period during the winter the harvest date of these flowers is postponed, which contributes to a production peak in spring.

Additional data are necessary to elucidate the effect of duration of flower growth, leaf emergence and flower initiation on flower production. Voigt Christensen (1971) found that a considerable number of flower buds are aborted and stated that a number of flower buds stay dormant.

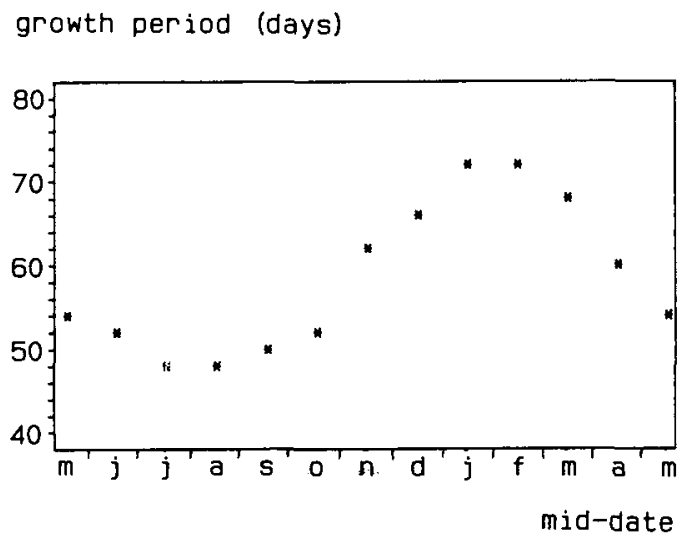

Fig. 2. The growth period (days) between flower emergence and harvest in Anthurium plotted against the mid-date. 


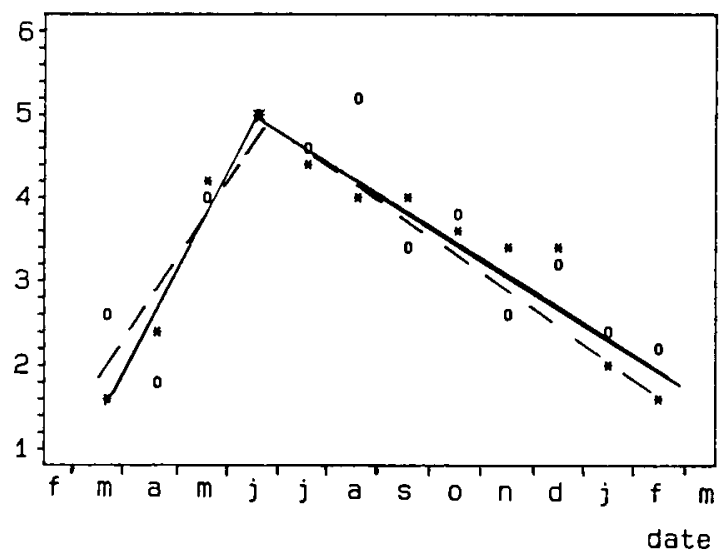

Fig. 3. Monthly production (mean number of flowers per $\mathrm{m}^{2}$ ) of Anthurium in the experimental nursery (O) and in 27 commercial nurseries $(x)$.

\section{Flower production}

Commercial flower production represents the seasonal effects on initiation, growth period and the level of abortion of flower buds. The year-round production (flowers per $\mathrm{m}^{2}$ ) of the total plant population in the experiment nursery is in good agreement with the average production of 27 commercial nurseries (Fig. 3). The correlation coefficients of the set from 27 nurseries are higher, as could be expected with the large number of nurseries, and justifies the use of these production data as representative for the seasonal effects. A production peak was found in the middle of June. These flowers emerged approximately 50 days earlier (Fig. 2). The maximum leaf production was found in about March-April (Fig. 1), so 2-3 months earlier than maximum flower production. It is likely that the flower is harvested 2-3 months after emergence of the leaf in whose axil the flower bud is initiated. Flower growth duration was 50 days, so the flower emerged 10-40 days after leaf emergence. To know accurately when leaf and flower buds are initiated in the meristem, microscopical dissection of growing points is necessary.

Mid-winter development proceeds generally much slower than in summer. This justifies the expectation that the period between the lowest leaf production and the lowest flower production increases considerably from summer to winter. The minimum flower production was registered mid-March, so the lowest leaf production should be expected in November-December. However, the relatively high leaf production in November-December did not perform a higher production in March (Fig. 2), which is probably due to flower bud abortion in mid-winter.

\section{Flower bud abortion}

During the experimental period an average of 18.9 shoots per $\mathrm{m}^{2}$ was found for the 
set of clones used. From the plastochron it is known that 4.5 leaves are emerging from each shoot per year. The potential flower production is therefore $4.5 \times 18.9=$ 85 flowers per $\mathrm{m}^{2}$ per year. The average annual production, however, was only 41.5 flowers, which implies an average abortion rate of approximately $50 \%$. The majority of these abortions occur during winter, as may be derived from data by Vonk Noordegraaf (1973), who restricted the amount of light in a greenhouse to $50 \%$ of the normal light level under Dutch meteorological conditions. This light interception resulted in an almost complete abortion from October until March and a $40 \%$ reduction in flower production during April-July. These abortions could explain a higher leaf production in our work in December compared to January and February but a lower flower production, leading to a production minimum in March.

The results indicate that normally applied heavy shading is harmful for an optimal production. Probably it would be better to reduce the light only at high radiation with a movable screen.

Lowering the winter temperatures may also be advantageous as, according to Vonk Noordegraaf (1973), flower emergence is stimulated by relatively low temperatures, at least in $A$. scherzerianum. This low temperature might give less abortion of flower buds, as the experiment of Vonk Noordegraaf was carried out under natural light conditions in the Netherlands. Another question is whether the number of shoots per $\mathrm{m}^{2}$ affects the abortion rate, as a higher density is restricting the amount of light per shoot.

\section{Conclusions}

The 11 clones of Anthurium used varied only slightly with respect to the response of growth and development to the season. Around 10 October an abrupt increase in leaf plastochron occurred, in which daylength was not involved. The decreasing leaf plastochron beyond 10 October resulted in a leaf production peak in MarchApril and a corresponding flower production in June. The unexpected low flower production in March may be the result of severe flower bud abortion in December.

As flower production depends on leaf emergence, leaf development should be promoted. Therefore artificial shading must be restricted to radiation peaks only. Movable screens are to be preferred above lime-shading.

During October-February the light intensity on the plant must be kept at the highest possible level to reduce flower bud abortion. This may be achieved by a lower plant density and the application of artificial light. Abortion may also be reduced by lower temperature.

\section{References}

Klapwijk, D., 1979. Seasonal effects on the cropping-cycle of lettuce in glasshouses during the winter, Scientia Horticulturae 11:371-377.

Voigt Christensen, O., 1971. Morphological studies on the growth and flower formation of Anthurium scherzerianum Schott and Anthurium andreanum Lind., Statens Forsogsvirksomhed i Plantekultur, København; 996. Beretning: 793-798.

Vonk Noordegraaf, C., 1973. Influence of temperature on flowering in Anthurium scherzerianum. Acta Horticulturae $31: 71-76$. 